\title{
EFFECT OF THE Pro12Ala POLYMORPHISM OF THE PEROXISOME PROLIFERATOR-ACTIVATED RECEPTOR $\gamma 2$ GENE ON LIPID PROFILE AND ADIPOKINES LEVELS IN OBESE SUBJECTS
}

\author{
Becer $E^{1,2, *}$, Çırakoğlu A
}

*Corresponding Author: Eda Becer, Ph.D., M.Sc., Department of Biochemistry, Faculty of Pharmacy, Near East University, Nicosia, Mersin 10, Turkey. Tel: +90-392-680-2000, Ext: 128. Fax:+90-392-680-2038. E-mail: edabecer@yahoo.com

\begin{abstract}
Peroxisome proliferator-activated receptor $\gamma(\operatorname{PPAR} \gamma)$ is a key regulator of metabolism, adipokines production and secretion. The aim of this study was to investigate the association between the PPAR 2 gene Pro12Ala polymorphism in obesity in terms of body mass index (BMI), lipid parameters, homeostasis model assessment of insulin resistance (HOMA-IR), serum lipid, leptin, adiponectin, resistin and chemerin levels. The study included 160 obese and 140 non obese subjects. The Pro12Ala polymorphism was determined by polymerase chain reaction-restriction fragment length polymorphism (PCR-RFLP). Serum lipid, leptin, adiponectin, resistin and chemerin levels were measured. No association was found between the Pro12Ala polymorphism and BMI. Strikingly, in the study group, obese subjects with the AA genotype had significantly higher triglycerides ( $p$ $=0.046)$ and resistin $(p<0.001)$ levels than those with the wild-type PP and heterozygous PA genotypes. Serum leptin and chemerin levels were significantly associated with Pro12Ala poymorphism in the obese and non obese groups ( $p$ $<0.01)$. In the obese group, subjects with the homozygous AAgenotype had significantly lower adiponectin $(p=0.010)$ activity than the PP genotype. Our results suggest that the $P P A R \gamma 2$ gene Pro12Ala polymorphism has no direct association with obesity but does have significant influences on lipid profiles and adipokines levels.
\end{abstract}

Keywords: Adipokines; Obesity; Peroxisome proliferator-activated receptor $\gamma(\operatorname{PPAR} \gamma)$; Polymorphism.

\footnotetext{
${ }^{1}$ Department of Biochemistry, Faculty of Pharmacy, Near East University, Nicosia, Mersin 10, Turkey

2 Experimental Health Science Research Center, Near East University, Nicosia, Mersin 10, Turkey

${ }^{3}$ Department of Medical Biology, Cerrahpasa Faculty of Medicine, Istanbul University, Istanbul, Turkey
}

\section{INTRODUCTION}

The proxisome proliferator-activated receptor $\gamma$ $(\operatorname{PPAR} \gamma)$ is a member of the nuclear hormone receptor superfamily and plays an important role in energy storage, adipocyte differentiation, insulin sensitization and fatty acid metabolism [1]. The PPAR $\gamma 1$, PPAR $\gamma 2$ and PPAR $\gamma 3$ are generated by separate promoters and 5' exons. Separate promoters and 5' exons generate three mRNA isoforms: PPAR $\gamma 1$, PPAR $\gamma 2$ and PPAR $\gamma 3$. The PPAR $\gamma 1$ and PPAR $\gamma 3$ mRNAs encode the same protein products, whereas PPAR 2 protein contains an additional $\mathrm{NH}_{2}$-terminal region composed of 30 amino acids. The $P P A R \gamma 1$ gene is expressed in nearly all cells, while PPAR $\gamma 2$ expression is limited mainly to adipose tissue [2].

Both PPAR $\gamma 1$ and PPAR $\gamma 2$ isoforms are an important adipogenic regulator and essential for the control of insulin sensitivity. However, PPAR $\gamma 2$ regulates response to nutrient intake and obesity. These characteristic properties make it a key molecule to be involved in the expression of adipokines such as leptin, adiponectin, resistin and chemerin, which may act as modulators of energy metabolism and insulin action [3]. Moreover, PPAR $\gamma 2$ mediates the expression of specific fat tissue cell genes that also participates in lipogenic pathways and adipocyte hypertrophy [4].

The PPAR 2 gene is located on chromosome $3 \mathrm{p} 25$ [5]. Several single nucleotide polymorphisms (SNPs) of the PPAR 2 gene have been identified and one of these poly-morphisms is Pro12Ala (rs1801282). The Pro12Ala polymorphism results from a cytosine to guanine substitution at nucleotide 34 of exon $\mathrm{B}$ and leads to a proline to alanine at position 12 of the PPAR $\gamma 2$ protein [6]. The alanine allele was shown to have reduced affinity for response element and lower capacity for activating target genes [7]. 
In recent years, several studies have focused on the association between the Pro12Ala polymorphism and complex traits such as obesity, type 2 diabetes mellitus (T2DM) and insulin sensitivity, have been reported $[8,9]$. Many studies have indicate that the alanine allele decreased risk of T2DM and increased insulin sensitivity $[10,11]$. However, studies on an association between the Pro12Ala polymorphism and obesity-related metabolic diseases have yielded inconsistent results $[8,12,13]$.

The mechanisms underlying the association of obesity and insulin sensitivity mainly involve altering the production of hormones and molecules related to adipose tissue and energy metabolism, such as leptin, adiponectin, resistin and chemerin. Therefore, the impact of the Pro12Ala polymorphism of the PPAR 2 gene on regulating adipokines expression will provide a better appreciation of the pathogenic mechanisms underlying obesity and associated comorbidities. However, the available data are still limited and conflicting. Thus, the aim of this study was to investigate the associations between the PPAR 2 gene Pro12Ala polymorphism, body mass index (BMI), lipid parameters, homeostasis model assessment of insulin resistance (HOMA-IR), serum leptin, adiponectin, resistin and chemerin levels in obese subjects versus non obese subjects.

\section{MATERIALS AND METHODS}

Subjects. This study was performed on two groups. One group was composed of 160 obese patients having a mean age of $41.4 \pm 8.19$ years and BMI $34.12 \pm 6.84 \mathrm{~kg} /$ $\mathrm{m}^{2}$. The second group was composed of 140 non obese subjects. The mean age of subjects was $39.6 \pm 9.63$ years and their mean BMI was $21.56 \pm 4.65 \mathrm{~kg} / \mathrm{m}^{2}$. Obese patients were recruited from the Endocrinology Department at the Famagusta Goverment Hospital, Famagusta, Cyprus, and non obese controls from the general population. None of the participants had hypertension, liver, kidney, thyroid, cardiovascular or any active inflammatory diseases and they were also questioned as to whether they were undergoing any medical therapy that might affect the lipid and glucose metabolism. The participants neither received any medications nor participated in any dietary or exercise programs. All subjects provided written informed consent before enrollment in the study, and the study was approved by the Near East University Research Ethics Committee.

Anthropometric Measurements. All the measurements were performed in the morning with the patients in a fasting state and anthropometric measurements, including weight $(\mathrm{kg})$, height $(\mathrm{m})$, hip circumference $(\mathrm{cm})$ and waist circumference $(\mathrm{cm})$ of each subject were measured barefoot and lightly clothed. Hip circumference was measured by placing a tape measure around the patient's hips at the level of the prominence over the greater trochanter of both femurs. Waist circumference was taken midway between the lowest rib (laterally) and the iliocristale landmark by flexible tape. The BMI was calculated as body weight $(\mathrm{kg})$ divided by the square of height $\left(\mathrm{m}^{2}\right)$ and obesity was defined as BMI $\geq 30 \mathrm{~kg} / \mathrm{m}^{2}$ [14].

Biochemical Parameters. Blood samples were obtained after an overnight fast. The levels of serum glucose, triglycerides, total cholesterol, high-density lipoprotein cholesterol (HDL-C) and low-density lipoprotein cholesterol (LDL-C) levels were measured by fully automated clinical chemistry analyzer (Abbott Architect C8000; Abbott Laboratories, Abbott Park, IL, USA). Fasting insulin concentrations were measured by electro chemiluminescence kit (Ref. 12017547) (Elecsys Corporation, Lenexa, $\mathrm{KS}, \mathrm{USA}$ ). Insulin resistance index were calculated using the HOMA-IR, as the product of fasting insulin $(\mu \mathrm{U} / \mathrm{mL})$ and fasting glucose $(\mathrm{mmol} / \mathrm{L})$ divided by 22.5 [15].

Serum leptin $(\mathrm{ng} / \mathrm{mL})$, resistin $(\mathrm{ng} / \mathrm{mL})$, chemerin $(\mathrm{ng} / \mathrm{mL})$ and adiponectin levels $(\mu \mathrm{g} / \mathrm{mL})$ were measured using commercially available enzyme linked immunosorbent assay (ELISA) kits (DRG International Inc., Springfield Townsip, NJ, USA for leptin and Biovendor Laboratory Inc., Brno, Czech Republic for adiponectin, chemerin and resistin) according to the manufacturers' protocols.

The PPAR $\gamma 2$ Gene Pro12Ala Polymorphism. In the screening phase, we assayed for the Pro12Ala (rs1801282) genomic variation of the PPAR 2 gene that exhibited associations with obesity, T2DM and insulin sensitivity in previous population studies [8-11]. The studies involving the PPAR 2 gene Pro12Ala polymorphism on adipokine levels such as leptin, adiponectin, resistin and chemerin in obese subjects was limited. For this reason, we decided to study the PPAR 22 gene Pro12Ala polymorphism.

Genomic DNA was extracted from whole blood by the salting out procedure [16]. Genotyping of the PPAR 2 gene Pro12Ala polymorphism (rs1801282) was carried out using the polymerase chain reaction-restriction fragment length polymorphism (PCR-RFLP) assay with previously described primer pairs [6]. The PCR reactions were performed on a total volume of $50 \mu \mathrm{L}$ using $1 \mu \mathrm{g}$ of genomic DNA, $0.4 \mu \mathrm{M}$ of each primer, $23.5 \mu \mathrm{L}$ nuclease-free water (Fermentas International Inc., Burlington, ON, Canada) and $25 \mu \mathrm{L}$ DreamTaq PCR Master Mix (Fermentas International Inc.). The PCR consisted of one cycle of initial denaturation for $5 \mathrm{~min}$. at $95^{\circ} \mathrm{C}$, followed by 30 cycles denaturation for $1 \mathrm{~min}$. at $95{ }^{\circ} \mathrm{C}$, annealing for $1 \mathrm{~min}$. at 
$56^{\circ} \mathrm{C}$ and extension for $1 \mathrm{~min}$. at $72^{\circ} \mathrm{C}$, and a final extension at $72{ }^{\circ} \mathrm{C}$ for $10 \mathrm{~min}$. Electrophoresis was conducted to confirm the $270 \mathrm{bp}$ PCR products. The PCR products were digested for 2 hours at $37^{\circ} \mathrm{C}$ with Bst $\mathrm{UI}$ restriction enzyme (Bsh 12361; Thermo Fisher Scientific, Waltham, MA, USA). Digest products were visualized on a $2.5 \%$ agarose gel stained with ethidium bromide. The expected products after digestion with $B s t \mathrm{UI}$ were $270 \mathrm{bp}$ for normal homozygotes, 227 and 43 bp for Pro12Ala homozygotes, and 270,227 , and $43 \mathrm{bp}$ for heterozygotes. The quality of SNP genotyping was verified by independently replicating the genotyping using randomly selected samples. The results from quality control were $100.0 \%$ in agreement with the initial genotyping results.

Statistical Analysis. Distribution of continuous variables in groups were expressed as mean \pm standard deviation (SD). Differences in baseline characteristics between groups were analyzed by Student's t-test. The $\chi^{2}$ analyses were used to compare the categorical variables, to compare the association between the genotypes and alleles in relation to obese and non obese subjects, and to test for deviation of the genotypic distribution from Hardy-Weinberg equilibrium (HWE). Analysis of variance (ANOVA) was used to compare means of continuous variables in the three genotype subgroups. The differences in the mean values of continuous variables in the three genotype subgroups were confirmed by the post hoc Tukey test. A $p$ value of less than 0.05 was considered statistically significant. All statistical analyses were performed with the Statistical Package for the Social Sciences (SPSS) version 15.0 (SPSS Inc., Chicago, IL, USA).

Table 1. Baseline characteristics of the studied populations.

\begin{tabular}{|l|c|c|c|}
\hline Parameters & Obese Subjects $(\boldsymbol{n}=\mathbf{1 6 0})$ & Non Obese Subjects $(\boldsymbol{n}=\mathbf{1 4 0})$ & $\boldsymbol{p}$ Value \\
\hline Age & $41.40 \pm 8.19$ & $39.6 .0 \pm 9.63$ & 0.081 \\
\hline BMI $\left(\mathrm{kg} / \mathrm{m}^{2}\right)$ & $34.12 \pm 6.84$ & $21.56 \pm 4.65$ & $<0.001$ \\
\hline Waist circumference $(\mathrm{cm})$ & $111.50 \pm 14.36$ & $84.73 \pm 7.39$ & $<0.001$ \\
\hline Hip circumference $(\mathrm{cm})$ & $122.10 \pm 15.94$ & $97.49 \pm 6.72$ & $<0.001$ \\
\hline Fasting glucose $(\mathrm{mg} / \mathrm{dL})$ & $104.22 \pm 19.38$ & $88.45 \pm 8.39$ & $<0.001$ \\
\hline Total cholesterol $(\mathrm{mg} / \mathrm{dL})$ & $236.35 \pm 31.73$ & $207.12 \pm 33.50$ & $<0.001$ \\
\hline LDL-cholesterol $(\mathrm{mg} / \mathrm{dL})$ & $138.90 \pm 27.36$ & $118.23 \pm 25.17$ & $<0.001$ \\
\hline HDL-cholesterol $(\mathrm{mg} / \mathrm{dL})$ & $47.63 \pm 8.41$ & $56.82 \pm 7.29$ & $<0.001$ \\
\hline Triglycerides $(\mathrm{mg} / \mathrm{dL})$ & $156.30 \pm 37.71$ & $105.10 \pm 31.90$ & $<0.001$ \\
\hline HOMA-IR & $4.25 \pm 1.78$ & $1.89 \pm 0.42$ & $<0.001$ \\
\hline Leptin $(\mathrm{ng} / \mathrm{mL})$ & $21.42 \pm 8.65$ & $7.82 \pm 2.53$ & $<0.001$ \\
\hline Adiponectin $(\mu \mathrm{g} / \mathrm{mL})$ & $7.81 \pm 2.84$ & $16.32 \pm 7.22$ & $<0.001$ \\
\hline Resistin $(\mathrm{ng} / \mathrm{mL})$ & $8.59 \pm 2.36$ & $5.28 \pm 2.34$ & $<0.001$ \\
\hline Chemerin $(\mathrm{ng} / \mathrm{mL})$ & $186.40 \pm 22.17$ & $138.20 \pm 25.76$ & $<0.001$ \\
\hline
\end{tabular}

BMI: body mass index; LDL-cholesterol: low-density lipoprotein-cholesterol; HDL-cholesterol: high-density lipoprotein-cholesterol; HOMA-IR: homeostasis model assessment of insulin resistance.

Data are expressed as means $\pm \mathrm{SD}$ and were compared by $t$-test.

Table 2. Genotype and allele frequencies of the PPAR 2 Pro12Ala polymorphism compared between obese and non obese subjects. [Results are given as $n(\%)$ ].

\begin{tabular}{|c|c|c|c|}
\hline & Obese Subjects $(\boldsymbol{n}=\mathbf{1 6 0})$ & Non Obese Subjects $(\boldsymbol{n}=\mathbf{1 4 0})$ & $\boldsymbol{p}$ Value $^{\mathbf{a}}$ \\
\hline Genotype & & & \\
PP (wild-type) & $98(61.25)$ & $81(57.86)$ & \\
PA (heterozygous) & $43(26.875)$ & $49(35.00)$ & 0.17 \\
AA (homozygous) & $19(11.875)$ & $10(7.14)$ & \\
\hline Allele frequency & $239(74.69)$ & $211(75.36)$ & 0.92 \\
P & $81(25.31)$ & $69(24.64)$ & \\
A & &
\end{tabular}

a The $p$ value was analyzed by the $\chi^{2}$ test. 
Table 3. Anthropometric and metabolic characteristics across PPAR 2 Pro12Ala genotypes of obese and non obese subjects. (Data are expressed as means \pm SD. For comparison of the subgroups, ANOVA was performed.)

\begin{tabular}{|l|r|r|r|r|r|r|r|r|}
\hline \multirow{2}{*}{ Parameters } & \multicolumn{4}{|c|}{ Obese Subjects } & \multicolumn{4}{c|}{ Non Obese Subjects } \\
\hline & PP $(n=98)$ & \multicolumn{1}{|c|}{ PA $(n=43)$} & \multicolumn{1}{|c|}{ AA $(n=19)$} & $p$ Value & PP $(n=81)$ & PA $(n=49)$ & AA $(n=10)$ & $p$ Value \\
\hline Age & $40.71 \pm 6.53$ & $42.20 \pm 8.92$ & $41.50 \pm 8.34$ & 0.540 & $38.90 \pm 7.23$ & $40.10 \pm 8.72$ & $39.70 \pm 8.67$ & 0.690 \\
\hline BMI $\left(\mathrm{kg} / \mathrm{m}^{2}\right)$ & $33.46 \pm 4.31$ & $34.42 \pm 6.94$ & $34.53 \pm 5.28$ & 0.500 & $20.64 \pm 3.67$ & $21.37 \pm 2.51$ & $22.53 \pm 2.84$ & 0.150 \\
\hline Waist circumference $(\mathrm{cm})$ & $111.74 \pm 11.32$ & $110.62 \pm 11.47$ & $111.95 \pm 10.94$ & 0.850 & $83.75 \pm 8.59$ & $85.46 \pm 8.73$ & $84.92 \pm 6.48$ & 0.530 \\
\hline Hip circumference $(\mathrm{cm})$ & $118.33 \pm 14.20$ & $122.49 \pm 15.48$ & $125.35 \pm 16.53$ & 0.091 & $96.33 \pm 5.12$ & $98.62 \pm 6.93$ & $97.41 \pm 6.84$ & 0.106 \\
\hline Fasting glucose $(\mathrm{mg} / \mathrm{dL})$ & $101.50 \pm 18.34$ & $105.31 \pm 16.52$ & $107.53 \pm 18.78$ & 0.270 & $89.58 \pm 7.49$ & $87.64 \pm 8.30$ & $88.23 \pm 8.16$ & 0.380 \\
\hline Total cholesterol $(\mathrm{mg} / \mathrm{dL})$ & $228.70 \pm 33.51$ & $235.29 \pm 32.38$ & $240.58 \pm 33.17$ & 0.260 & $198.95 \pm 30.10$ & $209.32 \pm 27.56$ & $212.86 \pm 31.68$ & 0.091 \\
\hline LDL-cholesterol $(\mathrm{mg} / \mathrm{dL})$ & $132.60 \pm 35.80$ & $139.91 \pm 26.20$ & $141.96 \pm 30.74$ & 0.326 & $116.83 \pm 22.30$ & $119.64 \pm 25.48$ & $118.82 \pm 24.90$ & 0.800 \\
\hline HDL-cholesterol $(\mathrm{mg} / \mathrm{dL})$ & $49.38 \pm 8.87$ & $47.54 \pm 8.21$ & $46.63 \pm 7.93$ & 0.290 & $57.84 \pm 7.72$ & $56.83 \pm 8.29$ & $54.38 \pm 8.46$ & 0.150 \\
\hline Triglycerides $(\mathrm{mg} / \mathrm{dL})$ & $146.12 \pm 37.20$ & $158.85 \pm 35.52$ & $164.60 \pm 36.14$ & $\mathbf{0 . 0 4 6}$ & $100.38 \pm 32.00$ & $104.42 \pm 30.20$ & $111.17 \pm 35.11$ & 0.520 \\
\hline Leptin $(\mathrm{ng} / \mathrm{mL})$ & $17.47 \pm 8.36$ & $20.31 \pm 8.62$ & $26.39 \pm 9.15^{\mathrm{b}}$ & $<\mathbf{0 . 0 0 1}$ & $6.15 \pm 2.64^{\mathrm{c}}$ & $7.53 \pm 3.18$ & $9.58 \pm 2.23$ & $<\mathbf{0 . 0 0 1}$ \\
\hline Adiponectin $(\mu \mathrm{g} / \mathrm{mL})$ & $8.73 \pm 2.75$ & $7.81 \pm 2.90$ & $6.78 \pm 2.28^{\mathrm{d}}$ & $\mathbf{0 . 0 1 0}$ & $18.58 \pm 8.92$ & $15.59 \pm 7.34$ & $14.64 \pm 7.69$ & 0.086 \\
\hline Resistin $(\mathrm{ng} / \mathrm{mL})$ & $6.74 \pm 2.73^{\mathrm{e}}$ & $8.82 \pm 2.46$ & $9.89 \pm 3.25$ & $<\mathbf{0 . 0 0 1}$ & $4.73 \pm 2.11$ & $5.42 \pm 2.53$ & $5.65 \pm 2.77$ & 0.180 \\
\hline Chemerin $(\mathrm{ng} / \mathrm{mL})$ & $176.52 \pm 23.80^{\mathrm{f}}$ & $186.79 \pm 22.30$ & $194.81 \pm 22.74$ & $\mathbf{0 . 0 0 2}$ & $130.55 \pm 22.40$ & $137.69 \pm 21.20$ & $145.83 \pm 22.31^{\mathrm{g}}$ & $\mathbf{0 . 0 4 7}$ \\
\hline HOMA-IR & $4.05 \pm 2.27$ & $4.11 \pm 1.92$ & $4.63 \pm 1.62$ & 0.290 & $1.86 \pm 0.73$ & $1.84 \pm 0.61$ & $1.95 \pm 0.52$ & 0.650 \\
\hline
\end{tabular}

SD: standard deviation; ANOVA: analysis of variance; PP: wild-type; PA: heterozygous; AA: homozygous; BMI: body mass index; LDL-cholesterol: low-density lipoprotein-cholesterol; HDL-cholesterol: high-density lipoprotein-cholesterol; HOMA-IR: homeostasis model assessment of insulin resistance.

${ }^{\text {a }}$ Significant difference from PP genotype by the post hoc Tukey test.

${ }^{\mathrm{b}}$ Significant difference from PP genotype by the post hoc Tukey test.

c Significant difference between PA genotype and AA genotype by the post hoc Tukey test.

d Significant difference between PA genotype and PP genotype by the post hoc Tukey test.

${ }^{\mathrm{e}}$ Significant difference from PP genotype by the post hoc Tukey test.

${ }^{\mathrm{f}}$ Significant difference between PA genotype and AA genotype by the post hoc Tukey test.

${ }^{\mathrm{g}}$ Significant difference between PA genotype and AA genotype by the post hoc Tukey test.

\section{RESULTS}

Descriptive statistics of anthropometric and metabolic characteristics of the study population are presented in Table 1. Obese and non obese subjects did not differ in age, while plasma glucose, total cholesterol, triglycerides, LDL-cholesterol, leptin, chemerin and resistin levels $(p<0.001)$ were significantly higher, and mean HDL-cholesterol $(p<0.001)$ levels were significantly lower in obese than in non obese subjects. Non obese subjects had significantly higher adiponectin levels and lower HOMA-IR than obese subjects $(p<0.001)$.

Analysis of the PPAR 2 gene yielded three variants of the genotype: PP (wild-type), PA (heterozygous), and AA (homozygous). The PPAR $\gamma 2$ genotype frequencies were calculated and are presented in Table 2. In obese subjects, the genotype frequencies were $61.25 \%$ for PP, $26.87 \%$ for $\mathrm{PA}$, and $11.87 \%$ for AA. The frequencies of PP, PA and AA genotypes were 57.86, 35.0, and 7.14\%, respectively, in non obese subjects. There was no significant derivation of genotypic distribution from HWE in non obese subjects $\left(\chi^{2}=0.46, p=0.61\right)$. However, The PPAR $\gamma 2$ genotype frequencies appear to be in $\operatorname{HWE}\left(\chi^{2}=13.38, \mathrm{p}=0.0051\right)$ in the obese group. The deficit of the PA genotype frequencies in obese subjects probably accounts for the deviation from HWE.

The PPAR 2 allele frequencies were calculated and are presented in Table 2. The proline allele of PPAR 2 (found in $74.69 \%$ of obese subjects and $75.36 \%$ of non obese subjects) and the alanine allele (found in $24.64 \%$ of non obese subjects and $25.31 \%$ of obese subjects) did not differ between obese and non obese subjects $(p=0.92)$.

There was no difference in age, BMI, HOMA-IR, waist or hip circumference, serum glucose, total cholesterol, LDLcholesterol, HDL-cholesterol, triglycerides, adiponectin, resistin or leptin levels between the three genotypes in non obese subjects. The PPAR 2 Pro12Ala polymorphism showed significant association with leptin $(p<0.001)$ and chemerin $(p<0.047)$ levels in non obese subjects (Table 3$)$. A post hoc analysis with Tukey's test for multiple comparisons revealed no significant difference between the leptin level mean values of AA and PA genotypes $(p>0.05)$. However, a significant difference was found between the mean values 
of the PP and PA genotypes and the PP and AA genotypes $(p<0.05)$. Post hoc analyses of the chemerin level means showed significant differences between the PP and AA genotypes, while the mean values of the AA and PA genotypes did not differ significantly in non obese subjects.

The PPAR 2 Pro12Ala polymorphism showed a significant association with triglycerides $(p<0.046)$, leptin ( $p$ $<0.001)$, chemerin $(p=0.002)$, adiponectin $(p=0.01)$ and resistin $(p<0.001)$ levels in obese subjects. The homozygous AA subjects' triglyceride values were significantly higher than the heterozygote PA and homozygote PP obese subjects. Post hoc comparisons showed that AA homozygotes had higher triglyceride mean values than those with the PP genotype $(p<0.05)$. Obese homozygous AA subjects showed significantly higher levels of leptin $(p<0.001)$ than those with the homozygous PP genotype and heterozygous PA genotype. Post hoc comparisons in obese subjects showed that AA homozygotes had significantly higher mean values than PP and PA, while no significant difference was found between the mean values of the PP and PA genotypes ( $p$ $>0.05)$. Additionally, obese subjects carrying an A allele showed significantly lower adiponectin levels $(p=0.01)$ than homozygous subjects with the P allele. Post hoc comparisons showed that AA homozygotes had lower adiponectin mean values than those with the PP genotype. The level of resistin was lower in obese subjects carrying a P allele. The post hoc analysis with Tukey's test for multiple comparisons revealed significant differences between the resistin mean values of PP and PA genotypes and the PP and AA genotypes $(p<0.05)$. However, no significant difference was found between the mean values of the AA and PA genotypes $(p>0.05)$. The wild-type PP subjects' chemerin values were significantly lower than the heterozygous PA and homozygous AA obese subjects. Post hoc comparisons in obese subjects showed that PP wild-type had significantly lower mean values than PA and AA, while no significant difference was found between the mean values of the PP and PA genotypes $(p>0.05)$. No significant differences in age, BMI, waist or hip circumference, HOMA-IR, serum glucose, HDL-cholesterol, LDLcholesterol, total cholesterol levels were observed between the three genotypes in obese subjects (Table 3).

\section{DISCUSSION}

Peroxisome proliferator-activated receptor $\gamma$ is a nuclear receptor that has a key role in energy storage, adipocyte differentiation, insulin sensitization and fatty acid metabolism [8]. To the best of our knowledge, this is the first report of the influence of Pro12Ala PPAR gene polymorphism genotypes on chemerin levels in obese and non obese subjects. Our results showed no correlation between the Pro12Ala PPAR $\gamma$ gene polymorphism and BMI, waist-hip circumference, HOMA-IR, total cholesterol, LDL-cholesterol, HDL-cholesterol and fasting glucose levels in both obese and non obese groups. On the other hand, the Pro12Ala polymorphism showed a significant association with triglyceride, adiponectin and resistin levels particularly in the obese group. Furthermore, we showed that the PPAR $\gamma$ gene polymorphism was associated with leptin levels in both the obese and non obese groups.

The PPAR 2 gene Pro12Ala polymorphism is the most studied genetic variant as potentially linked to the development of obesity. However, the results are still controversial. A number of studies have reported on the association of this variant with BMI and fat mass in different populations [17-19]. Ben Ali et al. [12] showed significant association between the PPAR 2 gene Pro12Ala polymorphism and obesity in non diabetic men of Tunisian origin. Also, Yao et al. [8] and Masud et al. [19] performed a meta-analysis to explain the association between Pro12Ala polymorphism and obesity. The results suggested that Pro12Ala polymorphism is a genetic modifier of obesity $[8,19]$. Contrary to these results, Gonzalez et al. [20] found a strong negative relationship between lower BMI. Deeb et al. [7] reported association of the Pro12Ala polymorphism in middle-aged non diabetic Finns, suggesting that the carriers of the alanine allele had significantly lower BMI.

Buzzetti et al. [3] also reported that this PPAR 2 gene was not associated with high BMI in the Italian population. Moffett et al. [21] showed no significant association between the Pro12Ala polymorphism and BMI in Hispanic and non Hispanic subjects. In the German study, the authors failed to find an association between this polymorphism and obesity [22]. Additionally, in a meta-analysis study including six studies from different populations, it was shown that there was no association between the Pro12Ala PPAR 2 gene polymorphism and obesity [23]. As in other studies, our results showed no association between the PPAR 2 gene polymorphism and BMI in Turkish Cypriots. Thus, our results may suggest that discrepancies in association studies could be related to ethnic differences, life style, nutritional factors, effects of gender and pleiotropic genotype, may also affect energy homeostasis and BMI.

Deeb et al. [7] first reported that the influence of the Pro12Ala polymorphism on lipoprotein lipase $(L P L)$ gene expression is most likely due to an effect on a functional PPAR response element in the LPL promoter and the $P P A R \gamma 2$ isoform had lower transactivation capacity on the $L P L$ gene in vitro [7]. In keeping with this result, Schneider 
et al. [24] demonstrated that the Pro12Ala substitution in PPAR 2 was associated with lower LPL activity in vivo. Moreover, Beamer et al. [18] showed that subjects with the alanine allele had higher triglyceride levels compared with PP wild-type genotype subjects, and Swarbrick et al. [22] observed higher levels of triglycerides in obese subjects with the alanine allele. In accordance with these previous findings, our results showed an association between the Pro12Ala polymorphism and triglyceride levels in obese subjects. The higher level of triglycerides seen only in the obese subjects with the Pro12Ala polymorphism may be due to larger adipose tissue mass, and therefore, relative intrinsic reduction of PPAR $\gamma 2$ activity.

Leptin and PPAR $\gamma 2$ are two important adipose tissue factors involved in energy metabolism regulation. It has been shown that activation of PPAR $\gamma$ inhibit leptin gene expression in adipocytes [25]. Moreover, heterozygous PPAR $\gamma$-deficient mice exhibit higher leptin levels than wildtype littermates [26]. Ben Ali et al. [12] also found an association between the Ala12 allele and higher levels of leptin in obese male subjects. Simón et al. [27] observed a increased serum leptin level in women with T2DM. In agreement with these studies, our results showed that subjects with the AA genotype for Pro12Ala in both the obese and non obese groups had significantly higher leptin levels than those with the PA and PP genotypes. It can be concluded that the Pro12Ala substitution on the structure of PPAR $\gamma 2$ may decrease functional antagonism effect of liganded PPAR $\gamma$ on the CCAAT/enhancer binding protein $\alpha(\mathrm{C} / \mathrm{EBP} \alpha)$ transactivation of the leptin promoter.

Peroxisome proliferator-activated receptor $\gamma$ is a modulator of numerous genes in the mature adipocyte, including those encoding adipokines which have a variety of functions to regulate physiological processes [28]. In mammalian cells, the PPAR $\gamma$ and $\mathrm{C} / \mathrm{EBP} \alpha$ are the main regulators of adipocyte specific expression of adiponectin [29]. Adi-ponectin is known to be potential sensitizer of insulin for liver and muscle. Levels of this adipokine are negatively correlated with a measure of adiposity and decreased with obesity and insulin resistance [30]. The PPAR $\gamma$ is a positive regulator of adiponectin expression and enhance adi-ponectin synthesis from adipocytes. The association of the PPAR 2 gene Pro12Ala polymorphism with adiponectin level has been widely examined in various studies, yet the results are still controversial. Mousavinasab et al. [31] found that AA genotype was associated with elevated adi-ponectin levels in young Finnish men. Ben Ali et al. [12] and Bhatt et al. [32] showed no significant association between the Pro12Ala and adiponectin levels. Contrary to this result, Takata et al. [33] and Yamamoto et al. [34] reported significant association between the PPAR 2 Ala12 allele and low adiponectin levels in young and healthy Japanese, respectively. Additionally, VázquezDel Mercado et al. [35], found that carriers of the alanine allele were observed to have decreased adiponectin levels in obese group. Considering our results, which showed that subjects with the AA genotype for PPAR 2 in the obese group have significantly higher adiponectin levels than those with the PA and PP genotypes, one could then speculate that the Pro12Ala substitution could be related to decreased binding affinity to the cognate promoter element in adiponectin gene.

Resistin is a potential link between obesity and insulin resistance or T2DM. To date, with respect to the resistin levels, one unique study demonstrated that the Pro12Ala polymorphism in Mexican-Mestizo population was not associated with resistin levels in both obese and non obese subjects [35]. In contrast, our results also showed that subjects with the AA genotype had significantly higher plasma resistin levels than the heterozygous PA and wildtype PP genotypes in obese subjects. In humans, resistin is expressed primarily by macrophages and PPAR $\gamma 2$ inhibits resistin synthesis [36]. The alanine allele was shown to have reduced efficiency in transactivating responsive promoter [7]. Thus, our results indicate that the alanine allele may decrease inhibition of resistin expression by PPAR $\gamma 2$ in obesity. All of the above suggests that high resistin and low adiponectin may cause insulin resistance and increase HOMA-IR levels in obese subjects who are carriers of the alanine allele.

Peroxisome proliferator-activated receptor $\gamma$ is regarded as the master regulator of adipocyte differantiation and it has close temporal relationship between chemerin during adipogenesis [37]. It has been demonstrated previously that knockdown of PPAR $\gamma$ expression abrogated both adipocyte differentiation and the induction of chemerin gene expression. Muruganandan et al. [38] demonstrated a direct role for PPAR $\gamma$ in regulating the expression of chemerin at the level of gene transcription. It has been reported that chemerin gene expression was decreased by PPAR $\gamma$ activation in mature bone marrow mesenchymal stem cell derivated adipocytes. Additionally, in vivo studies showed that PPAR $\gamma$ activation increased chemerin expression in white adipose tissue but not liver. Unfortunately, we found no published study of the association between Ala16Val PPAR 2 polymorphism genotypes and chemerin levels. Thus, this is the first study of the potential effect that substitution may cause impairment in PPAR $\gamma 2$ function by disturbing regulation of the Pro12Ala gene polymorphism on chemerin levels in obesity. Our results suggest that subjects with the AA genotype for Pro12Ala in both the obese and non obese groups had significantly 
higher plasma chemerin levels than those with the PA and PP genotypes. This shows that PPAR 2 carries the alanine allele at position 12 , it seems less active than the proline counterpart. These data suggest that the alanine variant of PPAR 2 may lead to an adverse effect on inhibition of chemerin expression in mature adipocytes and it could also increase plasma chemerin levels. Further studies are also necessary to better understand this relationship.

In the present study, the genotype and allele frequencies of obese and non obese groups were compared by the $\chi^{2}$ test, but no statistically significant differences were observed. There was no significant derivation of genotypic distribution from HWE in non obese subjects $(p=0.61)$. Whereas, the PPAR 22 genotype frequencies were shown to deviate from HWE $(p=0.0051)$ in the obese group. This showed that genetic diversity was deficient in this group because of the small number of sample size.

The main limitation of this study was the lifestyle characteristics, which have an influence on the relationship between gene variants and phenotypes. Another weakness was the relatively limited sample size, lack of body fat mass $\%$ measurement and PPAR $\gamma 2$ expression levels.

In conclusion, our results suggest that the PPAR 2 gene Pro12Ala polymorphism has no direct association with obesity but it does have significant influences on lipid profiles and adipokine expression. Based on the literature and our findings, the Pro12Ala polymorphism alone is not enough to be obese. Perhaps there is a cumulative effect in combining different factors like ethnicity, pleiotropic genotype effects and mitochondrial dysfunction, which altogether may regulate substrate metabolism, energy expenditure in the pathophysiology of obesity as well as roles in the mechanisms that affect adipogenesis and mature adipocyte function. In order to resolve this contradiction, further assessment of this with a larger cohort that includes all possible polymorphisms and environmental variables that might affect BMI, lipid metabolism and adipokine levels, is necessary.

Conflict of Interest. The author declares no conflict of interests in this study. The authors alone are responsible for the content and writing of this article.

\section{REFERENCES}

1. Stump M, Mukohda M, Hu C, Sigmund CD. PPAR $\gamma$ regulation in hypertension and metabolic syndrome. Curr Hypertens Rep. 2015; 17(12): 1-9.

2. Feige JN, Gelman L, Michalik L, Desvergne B, Wahli W. From molecular action to physiological outputs: Peroxisome proliferator-activated receptors are nuclear receptors at the crossroads of key cellular functions. Prog Lipid Res. 2006; 45(2): 120-159.

3. Buzzetti R, Petrone A, Ribaudo MC, Alemanno I, Zavarella S, Mein CA, et al. The common PPAR- $\gamma 2$ Pro12 Ala variant is associated with greater insulin sensitivity. Eur J Hum Genet. 2004; 12(12): 10501054.

4. Kubota N, Terauchi Y, Miki H, Tamemoto H, Yamauchi T, Komeda K, et al. PPAR $\gamma$ mediates high-fat diet-induced adipocyte hypertrophy and insulin resistance. Mol Cell. 1999; 4(4): 597-609.

5. Elbrecht A, Chen Y, Cullinan CA, Hayes N, Leibowitz Md, Moller DE, et al. Molecular cloning, expression and characterization of human peroxisome proliferator activated receptors $\gamma 1$ and $\gamma 2$. Biochem Biophys Res Commun. 1996; 224(2): 431-437.

6. Yen CJ, Beamer BA, Negri C, Silver K, Brown $\mathrm{KA}$, Yarnall DP, et al. Molecular scanning of the human peroxisome proliferator activated receptor $\gamma$ (hPPAR $\gamma$ ) gene in diabetic Caucasians: Identification of a Pro12Ala PPAR $\gamma 2$ missense mutation. Biochem Biophys Res Commun. 1997; 241(2): 270-274.

7. Deeb SS, Fajas L, Nemoto M, Pihlajamäki J, Mykkänen L, Kuusisto J, et al. A Pro12Ala substitution in PPAR $\gamma 2$ associated with decreased receptor activity, lower body mass index and improved insulin sensitivity. Nat Genet. 1998; 20(3): 284-287.

8. Yao YS, Li J, Jin YL, Chen Y, He LP. Association between PPAR- $\gamma 2$ Pro12Ala polymorphism and obesity: A meta-analysis. Mol Biol Rep. 2015; 42(6): 10291038 .

9. Tönjes A, Stumvoll M. The role of the Pro12Ala polymorphism in peroxisome proliferator-activated receptor $\gamma$ in diabetes risk. Curr Opin Clin Nutr Metab Care. 2007; 10(4): 410-414.

10. Moon MK, Cho YM, Jung HS, Park YJ, Yoon KH, Sung YA, et al. Genetic polymorphisms in peroxisome proliferator-activated receptor $\gamma$ are associated with type 2 diabetes mellitus and obesity in the Korean population. Diabet Med. 2005; 22(9): 1161-1166.

11. Ghoussaini M, Meyre D, Lobbens S, Charpentier G, Clément K, Charles MA, et al. Implication of the Pro12Ala polymorphism of the PPAR- $\gamma 2$ gene in type 2 diabetes and obesity in the French population. BMC Med Genet. 2005; 6(11): 1-8.

12. Ben Ali S, Ben Yahia F, Sediri Y, Kallel A, Ftouhi B, Feki M, et al. Gender-specific effect of Pro12Ala 
polymorphism in peroxisome proliferator-activated receptor $\gamma-2$ gene on obesity risk and leptin levels in a Tunisian population. Clin Biochem. 2009; 42(1617): 1642-1647.

13. Takata N, Awata T, Inukai K, Watanabe M, Ohkubo T, Kurihara S, et al. Pro12Ala substitution in peroxisome proliferator-activated receptor $\gamma 2$ is associated with low adiponectin concentrations in young Japanese men. Metabolism. 2004; 53(12): 1548-1551.

14. World Health Organization. Physical status: The use and interpretation anthropometry: Report of a WHO Expert Committee, WHO Technical Report Series, no. 854. Geneva, Switzerland: WHO. 1995; 321-344.

15. Matthews DR, Hosker JP, Rudenski AS, Naylor BA, Treacher DF, Turner RC. Homeostasis model assessment: Insulin resistance and $\beta$-cell function from fasting plasma glucose and insulin concentration in man. Diabetologia. 1985; 28(7): 412-419.

16. Miller SA, Dykes DD, Polesky HF. A simple salting out procedure for extracting DNA from human nucleated cells. Nucleic Acids Res. 1988; 16(3): 1215.

17. Tellechea ML, Aranguren F, Perez MS, Cerrone GE, Frechtel GD, Taverna MJ. Pro12Ala polymorphism of the peroxisome proliferator activated receptor- $\gamma$ gene is associated with metabolic syndrome and surrogate measures of insulin resistance in healthy men: Interaction with smoking status. Circ J. 2009; 73(11): 2118-2124.

18. Beamer BA, Yen CJ, Andersen RE, Muller, Elahi D, Cheskin LJ, et al. Association of the Pro12Ala variant in the peroxisome proliferator-activated receptor- $\gamma 2$ gene with obesity in two Caucasian populations. Diabetes. 1998; 47(11): 1806-1808.

19. Masud S, Ye S; SAS Group. Effect of the peroxisome proliferator activated receptor- $\gamma$ gene Pro12Ala variant on body mass index: A meta-analysis. J Med Genet. 2003; 40(10): 773-780.

20. Gonzalez Sanchez JL, Serrano Rios M, Fernandez Perez C, Laakso M, Martinez Larrad MT. Effect of the Pro12Ala polymorphism of the peroxisome proliferator activated receptor $\gamma-2$ gene on adiposity, insulin sensitivity and lipid profile in the Spanish population. Eur J Endocrinol. 2002; 147(4): 495-501.

21. Moffett SP, Feingold E, Barmada MM, Damcott CM, Marshall JA, Hamman RF, et al. The C161 $\rightarrow \mathrm{T}$ polymorphism in peroxisome proliferator-activated receptor $\gamma$, but not $\mathrm{P} 12 \mathrm{~A}$, is associated with insulin resistance in Hispanic and non-Hispanic white women:
Evidence for another functional variant in peroxisome proliferator-activated receptor $\gamma$. Metabolism. 2005; 54(11): 1552-1556.

22. Swarbrick MM, Chapman CM, McQuillan BM, Hung J, Thompson PL, Beilby JP. A Pro12Ala polymorphism in the human peroxisome proliferator-activated receptor- $\gamma 2$ is associated with combined hyperlipidaemia in obesity. Eur J Endocrinol. 2001; 144(3): 277-282.

23. Paracchini V, Pedotti P, Taioli E. Genetics of leptin and obesity: a HuGE review. Am J Epidemiol. 2005; 162(2): 101-114.

24. Schneider J, Kreuzer J, Hamann A, Nawroth PP, Dugi KA. The proline 12 alanine substitution in the peroxisome proliferator - Activated receptor- $\gamma 2$ gene is associated with lower lipoprotein lipase activity in vivo. Diabetes. 2002; 51(13): 867-870.

25. Hollenberg AN, Susulic VS, Madura JP, Zhang B, Moller DE, Tontonoz P, et al. Functional antagonism between CCAAT/enhancer binding protein- $\alpha$ and peroxisome proliferator-activated receptor- $\gamma$ on the leptin promoter. J Biol Chem. 1997; 272(8): 5283-5290.

26. Akune T, Ohba S, Kamekura S, Yamaguchi M, Chung UI, Kubota N, et al. PPAR $\gamma$ insufficiency enhances osteogenesis through osteoblast formation from bone marrow progenitors. J Clin Invest. 2004; 113(6): 846855.

27. Simón I, Vendrell J, Gutiérrez C, Fernández-Real JM, Vendrell I, Gallart L, et al. Pro12Ala substitution in the peroxisome proliferator-activated receptor- $\gamma$ is associated with increased leptin levels in women with type-2 diabetes mellitus. Horm Res. 2002; 58(3): 143-149.

28. Maeda N, Takahashi M, Funahashi T, Kihara S, Nishizawa H, Kishida K, et al. PPAR $\gamma$ ligands increase expression and plasma concentrations of adiponectin, an adipose-derived protein. Diabetes. 2001; 50(9): 2094-2099.

29. Moseti D, Regassa A, Kim WK. Molecular regulation of adipogenesis and potential anti-adipogenic bioactive molecules. Int J Mol Sci. 2016; 17(1): 1-24.

30. Duncan BB, Schmidt MI, Pankow JS, Bang H, Couper D, Ballantyne CM, et al. Adiponectin and the development of type 2 diabetes: The atherosclerosis risk in communities study. Diabetes. 2004; 53(9): 2373-2478.

31. Mousavinasab F, Tähtinen T, Jokelainen J, Koskela $\mathrm{P}$, Vanhala M, Oikarinen J, et al. Common poly-mor- 
phisms (single-nucleotide polymorphisms $\mathrm{SNP}+45$ and SNP+276) of the adiponectin gene regulate serum adiponectin concentrations and blood pressure in young Finnish men. Mol Genet Metab. 2005; 87(2): 147-151.

32. Bhatt SP, Misra A, Sharma M, Luthra K, Guleria R, Pandey RM. Ala/Ala genotype of Pro12Ala polymorphism in the peroxisome proliferator-activated receptor- $\gamma 2$ gene is associated with obesity and insulin resistance in Asian Indians. Diabetes Technol Ther. 2012; 14(9): 828-834.

33. Takata N, Awata T, Inukai K, Watanabe M, Ohkubo T, Kurihara S, et al. Pro12Ala substitution in peroxisome proliferator-activated receptor $\gamma 2$ is associated with low adiponectin concentrations in young Japanese men. Metabolism. 2004; 53(12): 1548-1551.

34. Yamamoto Y, Hirose H, Miyashita K, Nishikai K, Saito I, Taniyama M, et al. PPAR $(\gamma) 2$ gene Pro12Ala polymorphism may influence serum level of an adipocyte-derived protein, adiponectin, in the Japanese population. Metabolism. 2002; 51(11): 1407-1409.
35. Vázquez-Del Mercado M, Guzmán-Ornelas MO, Corona Meraz FI, Ríos-Ibarra CP, Reyes-Serratos EA, Ruíz-Quezada SL, et al. The 482Ser of PPARGC1A and 12Pro of PPARG2 alleles are associated with reduction of metabolic risk factors even obesity in a Mexican-Mestizo population. Biomed Res Int. 2015: $1-14$.

36. Patel L, Buckels AC, Kinghorn IJ, Murdock PR, Holbrook JD, Plumpton C, et al. Resistin is expressed in human macrophages and directly regulated by PPAR $\gamma$ activators. Biochem Biophys Res Commun. 2003; 300(2): 472-476.

37. Muruganandan S, Roman AA, Sinal CJ. Adipocyte differentiation of bone marrow-derived mesenchymal stem cells: Cross talk with the osteoblastogenic program. Cell Mol Life Sci. 2009; 66(2): 236-253.

38. Muruganandan S, Parlee SD, Rourke JL, Ernst MC, Goralski KB, Sinal CJ. Chemerin, a novel peroxisome proliferator-activated receptor $\gamma$ (PPAR $\gamma$ ) target gene that promotes mesenchymal stem cell adipogenesis. J Biol Chem. 2011; 286(27): 23982-23995. 
